\title{
Healing through the landscape
}

\begin{abstract}
This study investigates the significance of landscape therapy under the impact COVID-19 pandemic. Deurbanization and social distancing drives many city dwellers to their second homes (dacha) in the countryside or stimulates house trade and construction in the rural areas. This expands the possibilities of the body's recovery. One of the main methods is landscape therapy, along with the cultivation of their own agricultural products by the townspeople in the landscape-geochemical environment familiar to them. Of all natural components, water (natural mineral waters, mud, lakes, rivers, streams, waterfalls) has the greatest importance in the healing landscape concept. It is predicted that the COVID-19 pandemic should be perceived as a milestone in the reorientation of geography and ecology towards understanding human society in a continuous transformation.
\end{abstract}

Volume 5 Issue 4 - 202 I

\author{
Yuri N Golubchikov \\ Lomonosov Moscow State University, Faculty of Geography, \\ Department of Recreational Geography and Tourism, Russia
}

\begin{abstract}
Correspondence: Yuri N Golubchikov, Lomonosov Moscow State University, Faculty of Geography, Department of Recreational Geography and Tourism, Moscow, Russia, Email golubchikov@list.ru
\end{abstract}

Received: July 15, 202 I | Published: August 12, 202 |

Keywords: COVID-19 pandemic, landscape therapy, traditional lifestyle, rural tourism, second homes (dacha) recreation

\section{Opinion}

"A person's own observations of what is good for them and what is harmful is the best medicine for maintaining health" wrote Francis Bacon. ${ }^{1}$ Then when people succeeded in healing themselves, Aristotle understood that this would not be possible but through excellent understanding of the role nature has by its unity and uniqueness.

But man is more than nature. He has a spirit and a soul. And nature is also something more than physics, chemistry, or biology. It is also poetry, beauty and art: "It has a soul. It has freedom. It has love. It has a tongue". ${ }^{2}$

Everyone can establish for themselves the healing power of certain landscapes, trusting their sensations, experience and intuition. Moreover, depending on the state of the organism and the seasonal meteorological conditions, addictions to certain places can change. For some, sunrises are a spectacular sight, others do not notice them. Some general guidelines for choosing healing sites in a pandemic are still possible.

"And therefore, it must seem strange the amazing fact that we pay great attention to what we eat, what we drink, and what an insignificant, almost imperceptible interest we show in what kind of air we breathe ... This fact is in deep contradiction with the huge accumulation of theoretical and experimental knowledge of the human society, which speaks of the greatest physiological role of clean outof-town air". ${ }^{3}$ In the works of Chizhevsky ${ }^{3,4}$ it was shown that not all oxygen is beneficial. City air can contain enough oxygen, but there are no negatively charged oxygen ions in such oxygen. Without them, the work of the brain suffers, depression and apathy appear. In the city, the air is enriched with positively charged oxygen ions. Outside cities, positive oxygen ions accumulate in places of stagnant air: in lowlands, basements, in swampy valleys. Air stagnation is especially dangerous in winter and in cloudy weather, with fog.

As Chizhevsky stated, negatively ionized oxygen is the most wonderful and free medicine. Getting from the lungs into the blood, it saturates organs and tissues with energy. To activate the activity of oxygen in our body, it is necessary to learn not so much how to breathe correctly, which hundreds of manuals are devoted to, but rather where to breathe.
The air after a thunderstorm is highly saturated with negative oxygen ions, when it is filled with thousands of aromas of flowers, leaves, grass. Negative air ions are generated by mechanical fragmentation of water as a result of aerosolization of water droplets at an obstacle, aqueous surface, or by aerodynamic break-up during free fall. Therefore, the air is highly ionized during the surf or heavy rain, nearby fast mountain rivers and high waterfalls. Interacting with phytoncides secreted by trees, negative air ions effectively strengthen the innate immune system. ${ }^{5}$

All plants, and especially conifers, serve as an important source of negative oxygen ions. Almost sterile air is observed in a young pine forest, since pine is distinguished by a significant amount of phytoncides. It was found that volatile compounds secreted by foliage and needles - terpenes - have a positive effect on the formation of more so-called killer cells in the blood, which are responsible for the destruction of viruses, bacteria and even cancer cells that threaten health. It is worth taking a walk in the forest, and the number of such immune killer cells in the body rise by about $50 \%{ }^{6}$ In Japan, the practice of shinrin-yoku (forest baths) is widely practiced by breathing in the forest air with a full chest.

It has been known for over 1000 years in China that some places are rich in vitality and resources, while others are deserted, uninhabited and scarce. ${ }^{7}$ For instance, a compass was invented with the aim of finding those and other places, and not for navigation, as it is written in textbooks. The ancient Chinese art of Feng Shui (the doctrine of "winds and waters") is focused on the search for energyhealing places. According to this ancient teaching, the "life-giving energy of Qi" is concentrated to the greatest extent in the space between the mountains from the north and water from the south. It is good to rest and live here. It is even better if «the mountains surround in a semicircle, and the waters wash in a semicircle.» Then water and land form that wholeness, similar to which can be seen on the sign of Tao. Water is not necessarily the sea, a similar combination can form a river among the hills. In the European Middle Ages, Feng Shui was called geomantic geography. In essence, it is the ancient science of the geographic environment and how to harmonize with it. ${ }^{8}$

Calm water landscapes and gently curving shores have a positive effect on the human senses, healing and recovery. ${ }^{9}$ Wild swimming 
in open waters reduces fatigue, enhances mental health, and possibly boosts immunity. Contemporary studies in Ireland, Canada, Belgium, England, and Spain have shown a positive association of overall health with home proximity to bodies of water. ${ }^{10}$

Of all water bodies, the beneficial effects of the sea on humans have been the most studied. Water drops precipitate dust particles and the air over the sea contains fewer germs and viruses than over the land. Dry sand of sea, river or lake beaches (psammotherapy), amber particles may have tangible influence on health. Rhythmical noise of the surf, contemplation of waves and sunset over the sea has a calming effect on the nervous system. Even the simple inhalation of the sea air saturated with bromides and iodides is therapeutic. Their quantity increases many times during the storm. During a strong surf the sea becomes a giant natural aero-ionizer, saturating coastal air with tiny sea water droplets with electric charges and sea salts, negative ions of oxygen and ozone. ${ }^{11}$

The term "therapeutic landscape" emerged in English-language literature in the 1990s. ${ }^{12}$ It is defined as a metaphor for the self-healing processes that implicitly happen in specific places (or situations, conditions, settings, environments).$^{13}$ Healing is not synonymous with treatment. The goal of landscape therapy, like of tourism in general, can be considered to improve the quality of life, even if it goes against diseases and illnesses. As an indicator of a high quality of life, one can take good impressions from life with good health.

Medical tourism is associated with medical treatment. It is carried out for the purpose of visiting a medical institution and does not require natural conditions or natural healing resources. Health tourism (well-being tourism) is already focused on the treatment of a particular type of natural resource (balneological, mud, climatic). ${ }^{14}$ Landscape therapy is based on the healing power of the entire landscape complex, all components of the landscape.

Landscape therapy is not necessarily associated with moving outside the permanent place of residence, as tourism. It can be an ordinary hiking for long distances. It can be associated with the types of tourism with sport elements: hiking - a short hiking trip through scenic areas; trekking - a long journey through mountainous terrain with overnight stays in designated places.

It has been suggested that therapeutic landscapes are linked to salutogenesis, the source of the life forces that keep people healthy and enable them to recover and survive. The word "salutogenesis" has two components: the Latin "salutis" (health) and the Greek "genesis" (origin). Thus, the main task of salutogenesis is to find the sources of health-improving (salutogenic) forces. ${ }^{15}$ The organism is a part of nature and returns to it completely after death. Therefore, it is most appropriate to heal it by union with nature.

If in the light of the anthropic principle the whole Universe and the biosphere are tuned to the human being, we may expect this tuning from the earthly nature. ${ }^{16}$ A.L. Chizhevskiy asserted that "each atom of living matter is in constant continuous ratio with vibrations of atoms of environment - nature, each atom of living resonates to corresponding vibrations of atoms of nature". ${ }^{17}$ From here the possibilities of harmonization of organism with natural landscapes with the purpose of healing open.

That is why doctors in the past used to say to a sick person: "Leave everything and go to nature". It can be assumed that the importance of natural healing increases in times of various pandemics.

Landscape therapy encompasses not only the healing properties of the natural landscape, but also the accompanying elements of the cultural landscape, especially local foods and traditional remedies. It is closely intertwined with horticultural recreation and rural tourism. Countryside nature management, like rural tourism, combines two most contrasting spheres: agriculture, as the oldest and most basic foundation of the global economy, with tourism and recreation, one of the newest and fastest growing economic sectors. Dacha environmental management, rural tourism and landscape therapy have become a recreational response of the population to the COVID-19 pandemic.

In a pandemic, horticultural recreation can be viewed not only as an adaptive strategy to the projected economic downturn. There is a deep healing meaning in growing your own food. Until a hundred years ago, people mainly consumed products grown in the same geographic environment as they lived. Since then, all through hundreds of generations, a deep relation between food and humans has formed, up to the genetic level. Products from the centre of the emergence of cultivated plants, alien to the people, are, in a certain sense, genetically altered for them. Cells alien to the body are built from foreign products. New diseases come with them - cancer, stroke, atherosclerosis, diabetes, dysbacteriosis, pandemics. Their number is constantly growing, they are rapidly getting younger. At the same time, people blame anything for their illnesses, but not food. It is believed that earlier these diseases could not be diagnosed; hence there were no such names. But it is becoming more and more clear that they really did not exist. During World War II, when food was issued on ration cards or was grown independently, cardiovascular, cancer and other diseases plummeted across Europe. Hence, it follows that any organism needs the nutrition that is assigned to it by the nature of generations and the geographical habitat. Since immemorial times, numerous berries, nuts, salad and vegetable plants, mushrooms have been inherent in our diet. Compared to cultivated plants, they are not inferior, but rather significantly superior, in terms of nutrition and taste, we cannot even compare them, at all.

Closely related to the natural science components of human science, landscape therapy links medicine, psychotherapy and landscape science. However, around mutual intersection of many disciplines, as a rule, this area is pushed to the periphery of each of them. Hence, it is not surprising that we do not know of any books or teaching aids on the topic of landscape therapy, either in our country or abroad. There are small articles, but there is no monographic overview of the problem. There are many publications about the medicinal properties of forests and plants, seas, climate, rivers, but not about their natural combinations. With a huge abundance of books on the medicinal properties of individual plants, there are no books on phytocenosis treatment.

\section{Conclusion}

The pandemic serves as a turning point in the reorientation of geography and ecology towards understanding and advocating for nature preservation to be able to sustain human society in a continuous transformation. If even an insignificant part of those funds were allocated for the development of landscape therapy, which are aimed at the development of chemical and drug methods of treatment, then it would probably become an effective means of healing. The development of a methodology for the use of this primordially inherent healing remedy is still ahead.

\section{Acknowledgments}

I express my gratitude to the Editorial Analyst of MedCrave Group Swapna for her insistence on preparing and submitting this article. 


\section{Conflicts of interest}

The author declares that the research was conducted in the absence of any commercial or financial relationships that could be construed as a potential conflict of interest.

\section{References}

1. Bacon F. Experiments. In F. Bacon. Works in two volumes. Vol. 2. Moscow: Thought (Philosophical heritage). 1978. p. 575.

2. The Complete Poems of Tyutchev. In An English Translation by F.Jude Durham,. No.121. The Complete Poems of Tyutchev In An English Translation by F Jude. 2000. p. 125.

3. Chizhevsky AL. Atmospheric electricity and life. In Earth in the Universe. Moscow. Mysl, 1964. 422-442.

4. Chizhevsky AL. Aeroionification in the National Economy. Second ed. Moscow. Stroyizdat, 1989. p. 488

5. Grafetstätter C, Gaisberger M, Prossegger J, et al. Does waterfall aerosol influence mucosal immunity and chronic stress? A randomized controlled clinical trial. In Journal Physiological Anthropology. 2017;36:10 .

6. Arvay CG. The Healing Code of Nature: Discovering the New Science of Eco-Psychosomatics. / C.G. Arvay. Sounds True. 2018. p. 216.

7. Jiang S. Therapeutic landscapes and healing gardens: A review of Chinese literature in relation to the studies in western countries. In Frontiers of Architectural Research. 2014;3:141-153.

8. Hoon-key Yoon. Environmental Determinism and Geomancy: Two Cultures, Two Concepts. In Geojournal, 1982, No 6.1. p.77-80.
9. Majeed S, Ramkissoon H. Health, Wellness, and Place Attachment During and Post Health Pandemics. In Journal Frontiers in Psychology. 2020.

10. White MP, Elliott LR, Gascon M, et al. Blue space, health and well-being: A narrative overview and synthesis of potential benefits. In Environmental Research. 2020;191:14.

11. Nishino K. The Breath of Life: Using the Power of Ki for Maximum Vitality. Tokyo, New York, London: Kodansha International, 1997. p. 150.

12. Gesler WM. Therapeutic Landscapes: Medical Issues in Light of the New Cultural Geography. In Social Science \& Medicine. 1992;34:735-746.

13. Milligan C, Wiles J. Landscapes of Care. In Progress in Human Geography. 2010;34(6):736-754.

14. Connell J. Contemporary Medical Tourism: Conceptualization, culture and commodification. In Torism Management. 2013;34:1-13.

15. Völker S, Thomas K. The impact of blue space on human health and well-being - Salutogenetic health effects of inland surface waters: A review. In International Journal of Hygiene and Environmental Health. 2011;214:449-460

16. Golubchikov YN. Return to neptunism: review article. In International Journal Hydrology. 2021;5(1):1-7.

17. Chizhevskiy AL. Cradle of Life and Pulses of the Universe. In Russian cosmism: Antholgy of philosophical thought. In Russian Cosmism: The Anthology of Philosophical Thought / Compiled by S.G. Semenova, A.G. Gacheva; Preface to texts by A.G. Gacheva. - Ed. by A.G.Gacheva. M.: Pedagogica-press, 1993. - C. 317-327. 